\title{
Assessment of Policies, Laws, and Regulations Affecting the Contraceptive Needs of Adolescents in the Democratic Republic of the Congo
}

\author{
Dieudonné Mpunga Mukendi1 ${ }^{*}$, Eric Mafuta Musalu1, Fidèle Mbadu Muanda ${ }^{2}$, \\ Guy-Octave Lutumba ${ }^{3}$, Faustin Mukalenge Chenge ${ }^{4}$, Mala Ali Mapatano1, \\ Gilbert Utshudienyema Wembodinga ${ }^{1}$
}

\author{
${ }^{1}$ School of Public Health of Kinshasa, University of Kinshasa, Kinshasa, Democratic Republic of the Congo \\ ${ }^{2}$ National Program for Adolescent Health, Ministry of Public Health, Democratic Republic of the Congo \\ ${ }^{3}$ Faculty of Law, University of Kinshasa, Kinshasa, Democratic Republic of the Congo \\ ${ }^{4}$ School of Public Health of Lubumbashi, University of Lubumbashi, Lubumbashi, Democratic Republic of the Congo \\ Email: *mpungadieudonn@yahoo.fr
}

How to cite this paper: Mpunga Mukendi, D., Musalu, E.M., Muanda, F.M., Lutumba, G.-O., Chenge, F.M., Mapatano, M.A. and Wembodinga, G.W. (2020) Assessment of Policies, Laws, and Regulations Affecting the Contraceptive Needs of Adolescents in the Democratic Republic of the Congo. Health, 12, 1241-1261.

https://doi.org/10.4236/health.2020.129090

Received: September 2, 2020

Accepted: September 22, 2020

Published: September 25, 2020

Copyright $\odot 2020$ by author(s) and Scientific Research Publishing Inc. This work is licensed under the Creative Commons Attribution International License (CC BY 4.0).

http://creativecommons.org/licenses/by/4.0/

\begin{abstract}
Background: Poor regulation is a barrier to adolescents' accessing family planning (FP) services. We aimed to assess policies, laws, and regulations according to the contraceptive needs of adolescents in the Democratic Republic of the Congo (DRC). Methods: A mixed method study was conducted in 74 structures, including 13 administrative structures and 61 facilities offering FP. Data were collected through semi-structured interviews and document review. Using a health policy analysis framework, we analyzed the types of policies; their availability at the delivery points; the actors and the context of the policy formulation process. The content of policies was analyzed on the basis of WHO recommendations to ensure respect for human rights in the provision of contraceptive information and services. Results: Of the policies targeting the sexual and reproductive health (SRH), 18 were mainly focused on the FP of which 5 were the standards and directives; 5 implementing documents; 3 guidelines; 3 laws and 2 policies. Twelve documents were classified "important" for the FP extension. However, a few targeted adolescents and were translated into operational instructions for providers. Of 9 WHO recommendations, one was fully and two partially integrated into FP policies. Adolescents and FP providers were less involved in the policy formulation process. Conclusion: The FP regulation remains problematic in the DRC. FP policies are unsuitable to adolescents' expectation; they do not guarantee a secure and unrestricted access to FP services. The ministry of health should put
\end{abstract}


in place evidence-based regulations to improve access to SRH services by adolescents.

\section{Keywords}

Policies, Family Planning, Needs, Adolescents

\section{Background}

A significant number of adolescents worldwide are facing experiences of unmet needs in family planning (FP) [1]. The FP is an important option to reduce the incidence of teenage pregnancies and consecutive unsafe abortions that are common among adolescents [2] [3]. Contextual, situational, structural, cultural, and environmental factors influence the use of FP services by teenagers. To improve the provision and demand of FP by adolescents, the establishment of favorable policies is needed [4], guaranteeing teenagers' autonomy and privacy, as this is the case in some countries [5] [6].

Health policy is the ability of a group to agree on the priority and objectives to be addressed and the direction to be taken to achieve those goals [7]. Its formulation process, under the responsibility of health programs, requires a reflective and participative attitude, as well as the involvement of marginalized and targeted population [8] [9] [10]. Political options on FP may be translated into laws; guidelines; decrees; ministerial orders; actions; regulations and others, such as the government plans, programs, projects, or budgets [11]. Policies on the FP can help improving the uptake of FP if they are popularized.

To ensure that FP users' rights are taken into account in laws and regulations, local policies should guarantee the principles suggested by the World Health Organization (WHO) and the family planning 2020 initiative (FP2020). Among these universal values are counted the acceptability, availability and quality of contraceptive information and services; informed choice; equity and nondiscrimination; transparency and accountability; voice and participation of service users [12] [13]; their autonomy and empowerment [12]; the accessibility and privacy of contraceptive information and services [13]. WHO calls developing countries to develop specific guidelines to prevent early pregnancy and reproductive disorders in adolescents [14]. The policy analysis needs a participatory and rational process in order to discuss ways to achieve and evaluate the strategic objectives [4].

In order to reduce the incidence of unwanted pregnancies and unsafe abortions [2], the government of the Democratic Republic of the Congo (DRC) made a political commitment to expand the coverage in FP services [15]. Political leaders recognized the role of FP in the improvement of the community health and economic development [16]. Laws, plans and other policies supporting the FP were adopted [17] [18] [19] [20], leading to increased availability of FP services including the friendly FP services for adolescents [16] [21]. In 2009, only 
$20(3.9 \%)$ out of 515 health districts (HD) were offering adolescents' health activities; currently, $180(34.8 \%)$ out of 515 HD provide services that are adapted to the needs of teenagers [22]. However, the latest available data indicate that access to and uptake of contraceptive methods by adolescent girls remains low and unmet needs increasing [23]. Outside barriers are the lack of knowledge [24] [25], the misinformation and myths about contraception [26], the provider bias against the demand of the FP by adolescents [27] [28], and the financial barriers [29]. In the DRC, more than one uncoordinated specific health programs (SHP) are involved in the organization of the FP for adolescents [22] [30]. Other frequently cited bottlenecks preventing adolescents from the uptake of FP are the unavailability of significant number of friendly services for teenagers [31] and the frequent fragmentation of adolescent's SHP in many countries [32], including the DRC. In the meantime, few studies evaluated the policy formulation process, the regulation and the content of FP policies toward specific needs of adolescents in the DRC. On the basis of the WHO recommendations [13], we aimed to assess policies, laws and regulations of the FP according to the contraceptive needs of adolescents in the DRC.

\section{Context of the study}

In the DRC, adolescent FP services are managed by four central departments of the Ministry of Health $(\mathrm{MOH})$, each of which focuses on a specific aspect. The Department of Family and Special Groups' Health (DFSGH) coordinates the finalization of sexual and reproductive health (SRH) services and FP standards and guidelines that involve other public services and partners; the National Reproductive Health Program (NRHP) prepares the strategic and technical documents needed to organize the provision of FP and stimulate the demand for services [30]; the National Adolescents Health Program (NAHP) develops guidelines, standards, and strategies for the promotion and development of adolescent health [22]; and the National School Health Program (NSHP) prepares strategic and technical documents that organize school medicine and adolescent health education. All these departments target provincial structures, such as the provincial division of health $(\mathrm{PDH})$ and the provincial coordination of NSHP, NAHP, and NRHP; health districts (HD) and health facilities (HFs) (Figure 1).

\section{Methods}

\subsection{Study Design}

A mixed method study was conducted from April to December 2019 in 74 facilities, including 13 administrative structures at the central, provincial, and peripheral levels of the $\mathrm{MOH}$ identified by convenience sampling, and $61 \mathrm{HFs}$ offering the FP services and selected by simple random sampling.

\subsection{Selection of Surveyed Structures}

All visited structures were involved in the organization of the FP activities. They 


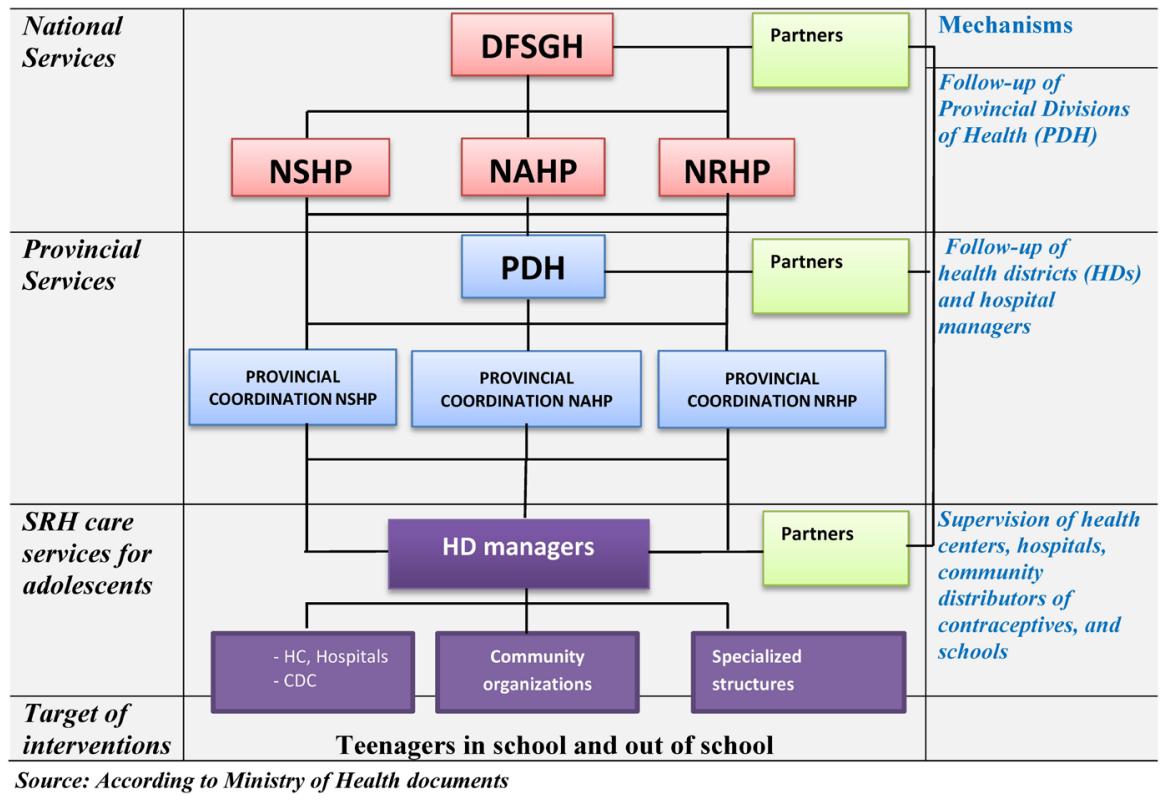

Figure 1. Organization of the health system around the family planning in the DRC.

came from the central administration of the $\mathrm{MOH}$, such as the DFSGH, the NAHP, the NSHP and the NRHP; and the provincial administration of the MOH, such as the Provincial Division of Health of Kongo Central and Kinshasa, and the corresponding provincial coordination of the NRHP selected for proximity. At the local level, the coordinating team of 3 health districts from Kinshasa (Matete, Lemba, Kisenso) and one HD from Kongo Central province (Gombe Matadi) and $61 \mathrm{HFs}$ were identified in a simple random manner.

\subsection{Techniques and Procedures for Data Collection}

The data were collected through ten semi-structured interviews with the managers of the visited organizations and by document review. Semi-structured interviews were conducted in the DFSGH, the NAHP, and the NRHP; the PDH of Kinshasa and Kongo central, and in HDs at the rate of one semi-structured interview per visited structure. They helped to collect the data on the process of coordination of SRH services and the establishment of FP policies within HFs. They also helped to understand the context and the process that conduct to the finalization of laws and policies on FP in the DRC. The characteristics of the interviewees of the visited structures are described in Table 1.

Using a semi-structured interview guide, the following themes were explored: knowledge of the types of policy documents on FP that exist or are needed in the DRC; the policy gap that exists in the organization of the FP for adolescents; the procedures of the development of FP policies, guidelines and standards; the main policy problems that arise when adolescents request FP in HFs; assessment of the availability and the use of standards, guidelines and other policies on FP by providers; the attitude of the providers toward adolescents requesting FP services.

Policy documents were collected from the archives of structures and through 
the websites of the Official Journal of the DRC (http://www.leganet.cd/), of the $\mathrm{MOH}$ (http://www.minisanterdc.cd/) and the Permanent Multi-sectoral Technical Committee of the PF (http://www.planificationfamiliale-rdc.net/). Based on collected data, we verified the types of policy documents; their availability at the delivery points; their content; the stakeholders involved; the context and the formulation process.

\subsection{Framework for Analyzing Health Policy Documents}

Several frameworks exist for health policy analysis. However, they differ from each other depending on the content under review; some focus on the stakeholder analysis; others focus on the content of the policy or only on the results [4]. To carry out this study, we used the health policy analysis framework developed by Walt and Gilson [33], which takes into account four elements: actors, contextual factors, process and content of the policy (Figure 2).

In order to assess FP policies, we made a choice to analyze the law laying down the fundamental principles relating to the organization of the public health and two normative documents (standards of health interventions adapted to adolescents

Table 1. Education and professional experience of the interviewees.

\begin{tabular}{ccccc}
\hline No. & Functions & Education & $\begin{array}{c}\text { Professional } \\
\text { Experience (Nb. } \\
\text { years) }\end{array}$ & Location (health pyramid) \\
\hline 1 & Expert & Public health practitioner & 10 & National MOH \\
2 & Expert & Public health practitioner & 2 & National MOH \\
3 & Expert & General practitioner & 7 & National MOH \\
4 & Manager & Public health practitioner & 6 & Provincial Division of Heath \\
5 & Manager & Public health practitioner & 8 & Provincial Division of Heath \\
6 & Manager & General practitioner & 2 & Health District \\
7 & Supervisor & Nurse & 8 & Health District \\
8 & Manager & General practitioner & 4 & Hospital \\
9 & Manager & Midwife & 11 & Heath Center \\
10 & Manager & Nurse & 5 & Heath Center
\end{tabular}

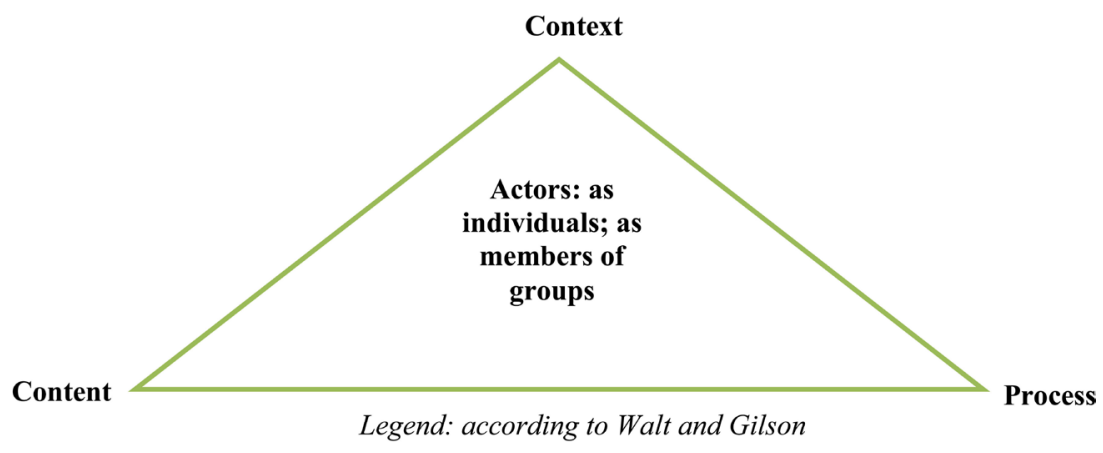

Figure 2. A model of health policy analysis. 
and young people and standards of FP interventions). Qualitative data helped to evaluate the first, second and third dimension of the policy analysis framework. To analyze the content of policies, we relied on a grid prepared on the basis of WHO recommendations for guaranteeing respect for human rights in the provision of FP information and services [13]. This document consists of nine recommendations and 24 sub-recommendations on FP that can be applied to the establishment of policies in FP. Thus, each policy document was examined in relation to each sub-recommendation. This analysis resulted in five categories of responses addressing the conformity of the content in relation to these recommendations. These categories were: 1) Normative guidelines specific to adolescents are present and in line with the sub-recommendations of the WHO;2) Normative guidelines for the general population, but relevant for adolescents, are present and in line with WHO sub-recommendations; 3) Normative guidance on WHO sub-recommendations is not present; 4) Normative guidelines specific to adolescents are present but do not agree with WHO sub-recommendations; 5) Normative guidelines for the general population, but relevant for adolescents, are present but do not agree with WHO sub-recommendations. We considered that a recommendation was fully, partially or not at all integrated in policy documents depending on whether all of the sub-recommendations, some or none were taken into account in the FP policies.

\subsection{Review of the Application of FP Regulations in HFs}

To audit whether the regulations of the FP for adolescents were applied or no through HFs, we first verified the availability of operational instructions on the FP that were adapted to adolescents. Then, the application of these regulations was assessed through the interviews with FP providers aiming to collect their intentions and attitudes towards the demand of the FP by adolescents. These interviews were combined to the observation of the counseling sessions on FP.

\subsection{Quality Control and Data Analysis}

An exhaustive inventory of existing policy documents was carried out. Each document was read, in order to identify the sub-recommendation(s) to which it was addressed and to ensure its compliance with the directives from the WHO. A form prepared following these recommendations helped to extract important information. The analysis consisted of calculating the proportion of recommendations and sub-recommendations incorporated into policy documents, the proportion of policies in phase with WHO recommendations that were translated into operational instructions and those made available in HFs.

A deductive thematic analysis was carried out on qualitative data. On the basis of the health policy analysis framework, the data from semi-structured interviews were grouped and analyzed following three themes: actors involved in the FP; the context; and the policy formulation process. From these, we identified open and axial codes. The analytical process involved splitting the data, followed 
by their analysis for similarities and differences by comparing all participants; similar concepts were labeled with the same name. Each concept was then defined in terms of a set of discrete properties and dimensions to add clarity and understanding of the policy environment. At the end of the analysis, important citations that fit in with the purpose of the study were used for illustration purposes.

\section{Results}

All identified structures were visited by the interviewees.

\subsection{Inventory of Policies Organizing the SRH and the FP in the DRC}

We inventoried 35 documents organizing the SRH in the DRC. Of these documents, few at least mentioned the FP; while 12 were classified as important for the FP extension in the DRC. These documents were laws, regulatory acts (e.g. decrees and ministerial orders), policies, standards, and guidelines. Most were developed by 2012; in their majority, they are intended for national and provincial health officials involved in the FP. Some of these documents deal with the general aspects of the organization of FP services (Table 2).

Of all reviewed documents targeting the FP, $5(27.8 \%)$ were the standards and directives; 5 (27.8\%) implementing documents; 3 (16.7\%) guidelines; 3 (16.7\%) laws and $2(11.1 \%)$ policies. However, only $4(22.2 \%)$ of policy documents were translated into operational instructions to be used in HFs. The majority of policy documents aimed to organize the FP for women aged 15 - 49; a few (22.2\%) targeted especially adolescent girls.

\subsection{FP Context and Stakeholders' Analysis}

The DRC is characterized by a pronatalist culture pushing women to progress in the future as mothers. The FP is used mainly for spacing than stopping births. The health system undergoes structural reforms focused on the decentralization. Recently (in 2018), several actors (public and private) were involved in the formulation and the enactment of the law laying down the fundamental principles relating to the organization of the public health, one out of five laws submitted by the $\mathrm{MOH}$. Faith-based providers, some civil society organizations and community leaders opposed to the FP actions in favor of adolescents. However, public providers, technical partners involved in FP and human rights organizations worked for the universal access to FP for both adolescents and adults. They made a plea and lobbying which helped taking into account some elements of the FP management in this law. Apart officials from the $\mathrm{MOH}$, provincial and local providers, as well as adolescents, were less involved in the formulation of the above-mentioned law and normative documents. Even since 2018, no clear operational instructions and guidelines have been made to address specific aspects of the FP (such as stimulation of the demand; financial accessibility; uptake of specific contraceptives by adolescents; rumors management, etc.). An official from 
Table 2. List of laws and other regulatory documents on family planning in the DRC.

\begin{tabular}{lllll}
\hline No. Category of document & $\begin{array}{l}\text { Type of } \\
\text { document }\end{array}$ & $\begin{array}{l}\text { Publication } \\
\text { date }\end{array}$ & Sources & $\begin{array}{l}\text { Recipients } \\
\end{array}$
\end{tabular}

Laws in phase with the family planning

1.1 Law No. 18/035 of December 13, 2018, laying Law down the fundamental principles relating to the organization of public health

1.2 Law No. 15/013 of August 1, 2015, on the implementation of the rights of women and parity

1.3 The laws on sexual violence (Law No. 06/018 of July 20, 2006, modifying and completing the decree of January 30 , 1940, bearing the Congolese Penal Code Law No. $06 / 019$ of July 20,2006 , modifying and completing the decree of August 6, 1959, relating to the code of the Congolese penal procedure)

\section{Policies of family planning}

2.1 National reproductive health policy

2.2 National policy on adolescent and youth health

\section{December 2018 Parliament}

Law

Law

July 2006

Parliament

August 2015 Parliament

Three levels of the

$\mathrm{MOH}$

Three levels of the $\mathrm{MOH}$

No

No

Three levels of the $\mathrm{MOH}$

$\begin{array}{lllll}\text { Policy } & \text { July 2008 } & \begin{array}{l}\text { Secretary General } \\ \text { for Health }\end{array} & \begin{array}{l}\text { Central and Provincial } \\ \text { MOH services }\end{array} & \text { No } \\ \text { Policy } & \text { November 2007 } & \begin{array}{l}\text { Secretary General } \\ \text { for Health }\end{array} & \begin{array}{l}\text { Central and Provincial } \\ \text { MOH services }\end{array}\end{array}$

3. Strategic documents integrating family planning

3.1 Second generation growth and poverty reduction strategy document (DSCRP2)

3.2 National health development plan 2019-2022

3.3 Multisectoral national strategic plan for family planning 2014-2020

3.4 National strategic plan for adolescent and youth health and wellbeing 2016-20

3.5 Strategic plan for Reproductive, Maternal, Newborn, Child, and Adolescent Health (RMNCAH)

\section{Guidelines, normative and other documents on FP}

4.1 Booklet of useful information on health services adapted to the needs of adolescents and young people

4.2 Adolescent and youth sexual and reproductive Directive health booklet for community health service providers, peer educators, and mentors

4.3 Standards of health interventions adapted to Standards adolescents and young people Directive

Implementing May 2011

document

Implementing March 2016

document

Implementing January 2014

document

Implementing March 2016

document

Implementing February 2019

document

Central

Government

Three levels of the

$\mathrm{MOH}$
May 2019

August 2017

Central

Government

Secretary General

for Health

Secretary General

for Health

Secretary General for Health

Three levels of the $\mathrm{MOH}$

Central and Provincial MOH services

Central and Provincial MOH services

Three levels of the $\mathrm{MOH}$

National Program Healthcare providers for Adolescent Health (PNSA)

National Program for Adolescent

Peer educators and Health (PNSA)

2012 Secretary General for Health
Central and Provincial MOH services; Health districts 


\section{Continued}

\begin{tabular}{|c|c|c|c|c|c|c|}
\hline 4.4 & Standards of family planning interventions & Standards & 2012 & $\begin{array}{l}\text { Secretary General } \\
\text { for Health }\end{array}$ & $\begin{array}{l}\text { Central and Provincial } \\
\text { MOH services; Health } \\
\text { districts }\end{array}$ & Yes \\
\hline 4.5 & $\begin{array}{l}\text { Standards and guidelines for use of the female } \\
\text { condom }\end{array}$ & Standards & 2012 & $\begin{array}{l}\text { Secretary General } \\
\text { for Health }\end{array}$ & $\begin{array}{l}\text { Provincial } \mathrm{MOH} \\
\text { services; Health } \\
\text { districts }\end{array}$ & No \\
\hline 4.6 & Female condom user guide & Guidelines & 2012 & $\begin{array}{l}\text { Secretary General } \\
\text { for Health }\end{array}$ & $\begin{array}{l}\text { Provincial MOH } \\
\text { services; Health } \\
\text { districts }\end{array}$ & No \\
\hline 4.7 & Collection of messages on family planning & Guidelines & 2012 & $\begin{array}{l}\text { Secretary General } \\
\text { for Health }\end{array}$ & $\begin{array}{l}\text { Provincial } \mathrm{MOH} \\
\text { services; Health } \\
\text { districts }\end{array}$ & Yes \\
\hline 4.8 & $\begin{array}{l}\text { Technical sheet for medical care in family } \\
\text { planning }\end{array}$ & Guidelines & 2012 & $\begin{array}{l}\text { National } \\
\text { Reproductive } \\
\text { Health Program } \\
\text { (PNSR) }\end{array}$ & Healthcare providers & Yes \\
\hline
\end{tabular}

a central structure of the $\mathrm{MOH}$ said this: "we are facing rumors about the side effects of contraceptives in adolescents, however, rumor management tools which can help improve awareness and education are not available in facilities" (CB, 10 years of experience).

\subsection{Process and Content of FP Policies in the DRC}

The process that conducted to the establishment of the FP first law and normative documents took up to 12 years. According to the majority of interviewees, the strategy for the policy development was not well refined; some main stakeholders from the government and parliament were not involved at the early stages of lawmaking. An interviewee said: "the process conducting to the adoption of new laws is long and complex in the DRC. Over the years we have been preparing more than one public health bill. However, they have never been discussed in parliament. Therefore, the health sector remained for years without laws. It was in 2018 that officials of the $\mathrm{MOH}$, in collaboration with sectoral partners, resumed pleading with national deputies until the promulgation of the first health sector law" (AD, general practitioner, 7 years of experience).

The problems raised by unwanted pregnancies and consecutive unsafe abortions for both adult women and adolescent girls are not well stated in this law. In addition, the law just refers to women of childbearing age without specifying that these are women aged 15 to 49 . Apart from the general principles set out in the law; no implementing measure (specific laws, decrees and ministerial orders) out of 17 identified has yet been finalized. The impact of this law to improving the uptake of the FP by adolescents aged $15-19$ is likely to be marginal.

\subsection{Assessment of the Content of Family Planning Policy Documents}

The achievement of WHO recommendations and sub-recommendations on the 
rights to access to FP information and services was assessed by analyzing the content of each policy document in Table 2. We present the synthesis from this analysis, with focus on the integration of each recommendation and sub-recommendations in policy documents (Table 3).

Of nine WHO recommendations on the right of accessing to FP information and services by adolescents, one (11\%) was fully integrated into one or more policy documents, two (22\%) were partially integrated, and six (67\%) were not yet integrated into national policies on FP. On the other hand, of the $24 \mathrm{WHO}$ sub-recommendations, 5 (21\%) were included in FP policies with focus on adolescents' aspects, 6 (25\%) sub-recommendations integrated into national policy documents do not specifically target adolescents, and 12 (50\%) were not integrated. One (4\%) sub-recommendation integrated in policies was inconsistent with orientations from WHO.

\section{Recommendation of the non-discrimination}

This recommendation was fully integrated through national policies; such as the constitution of the DRC; the law laying down the fundamental principles relating to the organization of the public health; and the law on the implementation of the rights of women and parity. The last law states: "... the public authorities shall ensure the elimination of all forms of discrimination against women and ensure the protection and promotion of their rights". And "...the State shall develop a policy which encourages, by means of incentives, the construction, from public or private funds, of information, training, promotion and defense centers for the rights of women and young girls in each village, group, chiefdom, sector, district, commune and city". Law No. 15/013 concerning the implementation of the rights of women and parity, of August 1, 2015.

\section{Accessibility of contraceptive information and services}

This recommendation was partially integrated. Two sub-recommendations (3.1 and 3.4) are included respectively in "the National Strategic Plan for Adolescent and Youth Health and Wellbeing 2016-20" and "the law on sexual violence". However, the sub-recommendations 3.2, 3.6 and 3.9 are integrated in policy documents only in aspects concerning adult women.

\section{Informed decision-making}

This recommendation is partially integrated; one in two sub-recommendations (sub recommendation 6.1) has been integrated in the law No. 15/013 concerning the implementation of the rights of women and parity.

\subsection{Review of the Application of FP Regulations and Policies in HFs}

Of all policy documents, 4 (18.2\%) in phase of the WHO recommendations were translated into operational instructions. However, we noticed that 15 (24.6\%) out of $61 \mathrm{HFs}$ had at least one guideline/operational instructions for adolescent sexual health. None of the HFs had all of the operational instructions at the same time. In $15 \%$ of HFs, providers were trained in adolescent SRH; in 13\% they were trained in specific aspects of the FP for adolescents; and in 13\% they were 
Table 3. Integration of WHO recommendations to ensure respect for human rights in the provision of contraceptive information and services to adolescents in the DRC's policy documents.

WHO recommendations and sub-recommendations

\section{Categories}

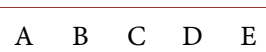

1. Non-discrimination

Totally integrated

1.1 Recommend that access to comprehensive contraceptive information and services be provided equally to everyone $\mathrm{X}$ voluntarily, free of discrimination, coercion, or violence (based on individual choice)

1.2 Recommend that laws and policies support programs to ensure that comprehensive contraceptive information and $\mathrm{X}$ services are provided to all segments of the population. Special attention should be given to disadvantaged and marginalized populations in their access to these services

2. Availability of contraceptive information and services

2.1 Recommend integration of contraceptive commodities, supplies, and equipment, covering a range of methods, including emergency contraception, within the essential medicine supply chain to increase availability. Invest in strengthening the supply chain where necessary in order to help ensure availability

3. Accessibility of contraceptive information and services

Not integrated

$\mathrm{X}$

Partially integrated

3.1 Recommend the provision of scientifically accurate and comprehensive sexuality education programs within and $\mathrm{X}$ outside of schools that include information on contraceptive use and acquisition

3.2 Recommend eliminating financial barriers to contraceptive use by marginalized populations, including adolescents and the poor, and make contraceptives affordable to all

3.3 Recommend interventions to improve access to comprehensive contraceptive information and services for users and potential users with difficulties accessing services (e.g. rural residents, urban poor, adolescents). Safe abortion information and services should be provided according to existing WHO guidelines (Safe abortion: technical and policy guidance for health systems, 2nd edition)

3.4 Recommend special efforts be made to provide comprehensive contraceptive information and services to displaced $\mathrm{X}$ populations, those in crisis settings, and survivors of sexual violence, who particularly need access to emergency contraception

3.5 Recommend that contraceptive information and services, as a part of sexual and reproductive health services, be offered within HIV testing, treatment, and care provided in the health-care setting

3.6 Recommend that comprehensive contraceptive information and services be provided during antenatal and postpartum care

3.7 Recommend that comprehensive contraceptive information and services be routinely integrated with abortion and post-abortion care

3.8 Recommend that mobile outreach services be used to improve access to contraceptive information and services for populations who face geographical barriers to access

3.9 Recommend elimination of third-party authorization requirements, including spousal authorization for individuals/women accessing contraceptive and related information and services

3.10 Recommend provision of sexual and reproductive health services, including contraceptive information and services, for adolescents without mandatory parental and guardian authorization/ notification, in order to meet the educational and service needs of adolescents

4. Acceptability of contraceptive information and services

4.1 Recommend gender-sensitive counseling and educational interventions on family planning and contraceptives that are based on accurate information, that include skills building (i.e. communications and negotiations), and that are tailored to meet communities' and individuals' specific needs

4.2 Recommend that follow-up services for management of contraceptive side-effects be prioritized as an essential component of all contraceptive service delivery. Recommend that appropriate referrals for methods not available on site be offered and available

5. Quality of contraceptive information and services
$\mathrm{X}$

$\mathrm{X}$

$\mathrm{X}$

$\mathrm{X}$

$\mathrm{X}$

$\mathrm{X}$

Not integrated

$\mathrm{X}$

$\mathrm{X}$

Not integrated 


\section{Continued}

5.1 Recommend that quality assurance processes, including medical standards of care and client feedback, be incorporated routinely into contraceptive programs

5.2 Recommend that provision of long-acting reversible contraception (LARC) methods should include insertion and removal services, and counseling on side effects, in the same locality

5.3 Recommend ongoing competency-based training and supervision of health-care personnel on the delivery of contraceptive education, information, and services. Competency-based training should be provided according to existing WHO guidelines

6. Informed decision-making

Partially integrated

6.1 Recommend the offer of evidence-based, comprehensive contraceptive information, education, and counseling to $\mathrm{X}$ ensure informed choice

6.2 Recommend every individual is ensured an opportunity to make an informed choice for their own use of modern contraception, including a range of emergency, short-acting, long-acting, and permanent methods, without discrimination

7. Privacy and confidentiality

7.1 Recommend that privacy of individuals be respected throughout the provision of contraceptive information and services, including confidentiality of medical and other personal information

8. Participation

8.1 Recommend that communities, particularly people directly affected, have the opportunity to be meaningfully engaged in all aspects of contraceptive program and policy design, implementation, and monitoring

9. Accountability

9.1 Recommend that effective accountability mechanisms be put in place and are accessible in the delivery of contraceptive information and services, including monitoring and evaluation, and remedies and redress, at the individual and system levels

9.2 Recommend evaluation and monitoring of all programs to ensure the highest quality of services, and respect for human rights must occur

Recommend that, in settings where performance-based financing (PBF) occurs, a system of checks and balances be in place, including assurance of non-coercion and protection of human rights. If PBF occurs, research should be conducted to evaluate its effectiveness and its impact on clients in terms of increasing contraceptive availability
$\mathrm{X}$

Not integrated

$\mathrm{X}$

Not integrated

$\mathrm{X}$

Not integrated

$\mathrm{X}$

$\mathrm{X}$

trained in both adolescent SRH and FP (Figure 3).

Available policy documents were the standards of health interventions adapted to adolescents and young people; the standards of FP interventions; the collection of messages on FP and the technical sheet for medical care in FP. Twenty percent of HFs had FP data sheets and 51\% had materials for SRH education (Figure 4).

The majority of policies were not applied within HFs. The low availability of operational instructions appeared to be a major problem among FP providers. A nurse in charge of a health center declared: "we find it difficult to prescribe some contraceptives to adolescents who come alone; our partner asks us to do it but we have no written instructions on what and how to do it. So, we hesitate" (MM, Health center manager, Kongo Central).

In the absence of clear written operational instructions, some providers are reluctant to prescribe contraceptives to adolescent girls. They feel they are not secure enough to do this. It sometimes happens that the prescription of contraceptives to adolescents leads to the arrest of the provider by the security services 


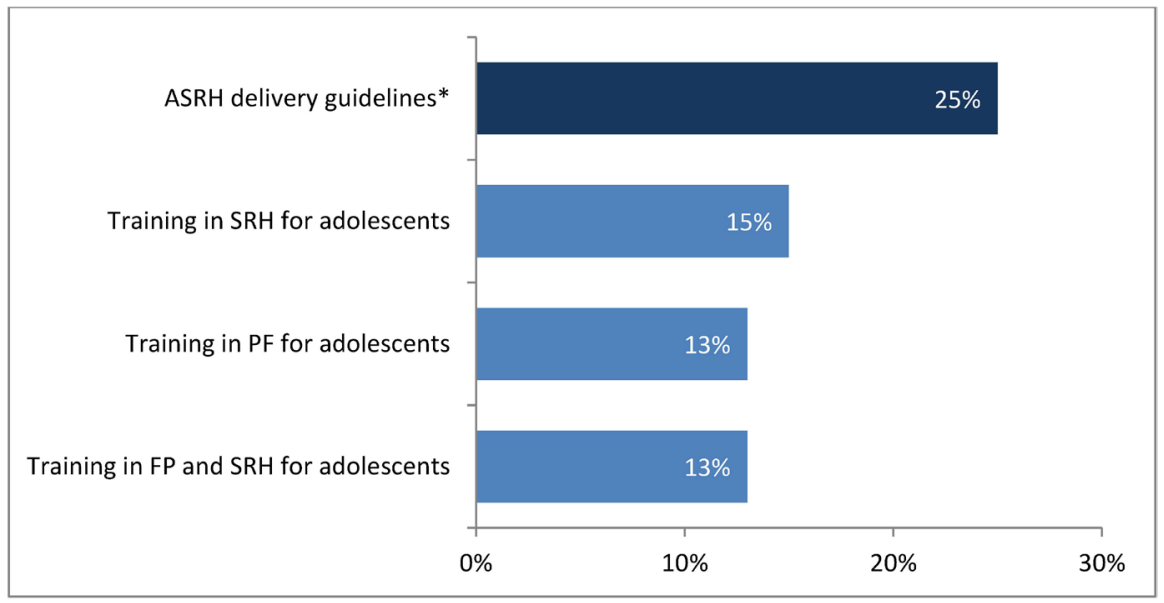

*Adolescents Sexual Reproductive Health (ASRH) guidelines.

Figure 3. Availability in health facilities of guidelines and trained providers in Adolescent Sexual and Reproductive Health $(\mathrm{N}=61)$.

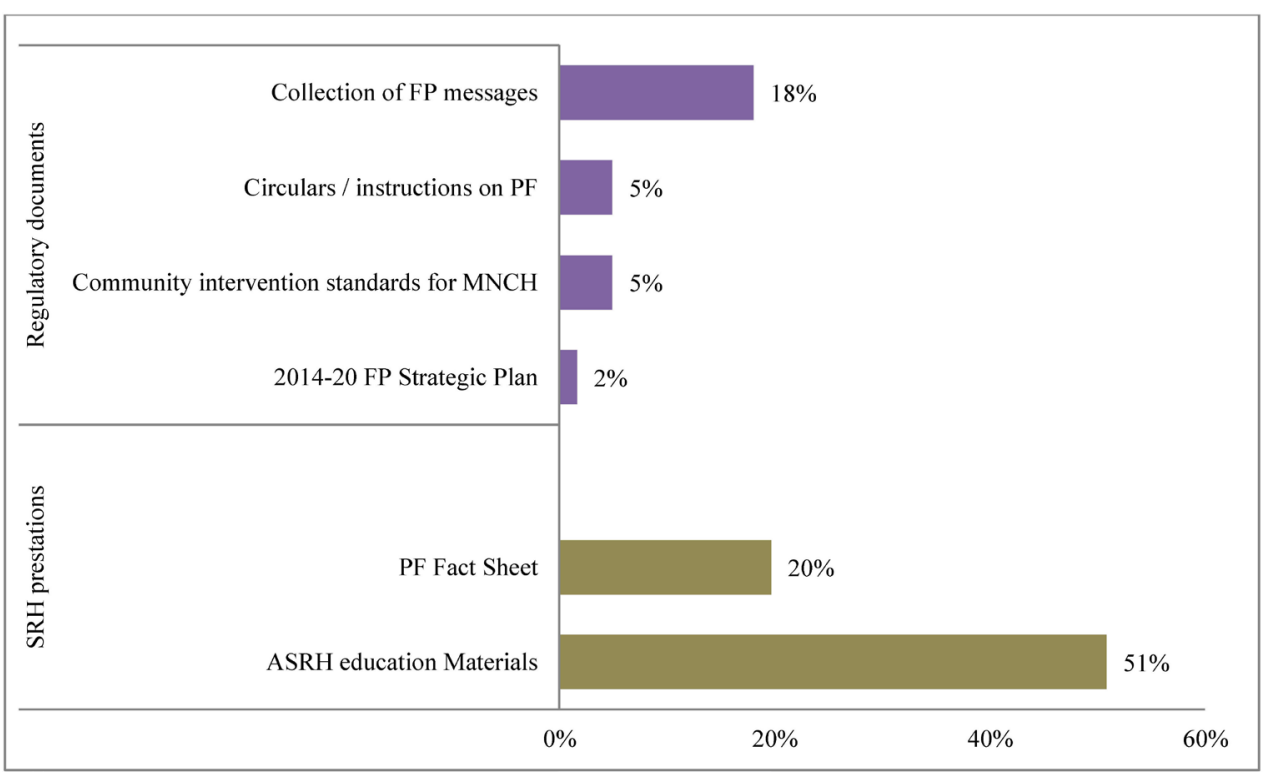

Figure 4. Types of family planning policy documents available within HFs $(\mathrm{N}=61)$.

which consider him to have committed an offense as shown in this statement:

"In the past few days, one of our nurses had placed an implant in a teenage girl at her request. After this activity, the teenager's parent went to complain to the security services, which led to a brief arrest of the nurse" (VM, Expert, DPS of Kinshasa).

\section{Discussion}

The main results of this study showed that in the DRC, many policy documents, such as the FP strategic plan; the growth and poverty reduction strategy document; the reproductive, maternal, newborn, child, and adolescent health strategic plan; and standards for FP interventions are intended to improve the delivery of FP services. However, they do not contain actions clearly intended to improve 
access to and use of FP by adolescents. Family planning policies in the DRC are not in phase with the WHO recommendations to ensure respect for human rights in the provision of contraceptive information and services. Indeed, six out of nine of these recommendations are not yet integrated into policies. These results highlight the weak regulation of FP in the DRC. This situation could be due to the weak coordination of the stakeholders involved in the FP and adolescent health in the DRC. Indeed, in the MOH, four public structures-the DFSGH, NRHP, NAHP, and NSHP-are concerned by the issue of FP and adolescent health regulation. They are committed to provide support to the provinces in the process leading to the finalization of operational instructions in FP and adolescent health [9] [10] [17] [34]. The low availability of the operational instructions in HFs raises the questions about the quality of the support provided. Even, there are multiple coordination mechanisms of the SRH and FP in the health sector. In fact, at the national level, FP partners are coordinated by the reproductive, maternal, newborn, child, and adolescent health task force and by the permanent multi-sectoral technical committee for FP (CTMP/PF) [35]. They validate FP policies prior to their adoption by the health sector technical coordination committee (CCT-SS). In the provinces, the technical working group (GTT) and the provincial health sector steering committee (CPP-SS) are in charge of contextualizing national policies. At the local health system level, supervision and monitoring meetings help to coordinate FP activities in health districts (Figure 5).

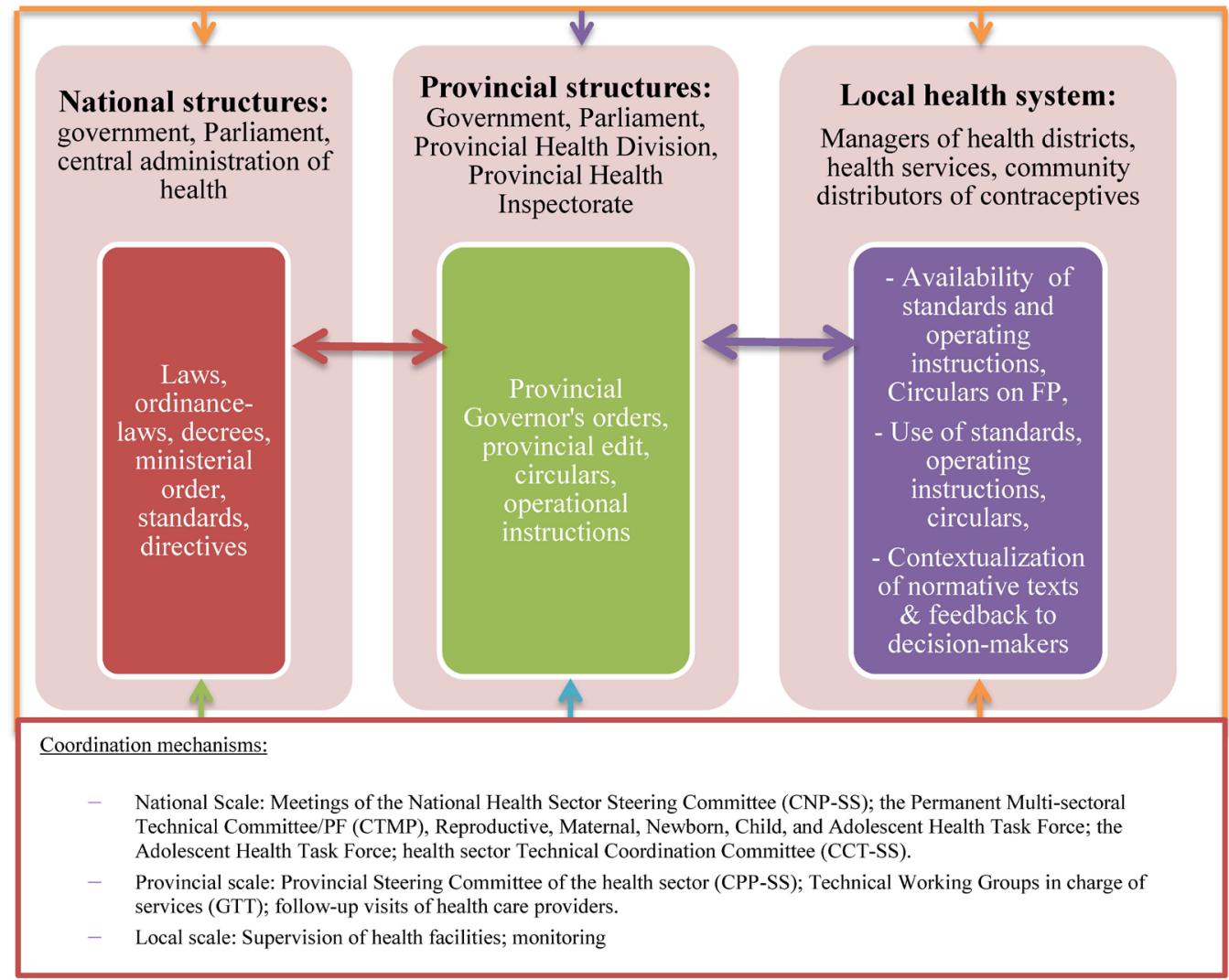

Figure 5. Framework for regulating family planning services in the DRC. 
The DRC's national health development plan 2019-22 links the weak regulation of the health sector to the dysfunctional structures in charge of regulation [19]. However, the incoordination of adolescents' health programs is also observed in other health systems, as is the case in India [31]. The weak regulation of FP results in the co-existence of FP policies that are ambiguous or even contradictory; thus, hindering access to and uptake of FP by adolescents. The law on fundamental principles on public health establishing the FP does not clearly define the woman of childbearing age [18]; this situation is pushing to various interpretations, tending to exclude adolescent girls aged 15 to 17 , especially since the law on the protection of children covers youths up to the age of majority fixed at 18 years. At the end of the law on child, adolescents under 18 years were placed under parental authority with regard to their health; which means that children under 18 years cannot decide for themselves to use FP services and methods [36]. Apart the child protection law, some provisions in the family code of the DRC [37] which set aside the automatic emancipation of children under 18 years from the marriage or getting job also could limit the access and uptake of FP by adolescents. In public health, the women of childbearing age encompass the age group of 15 to 49 years. In view of these facts, there is no legal basis to justify and protect the demand of FP services or to prescribe contraceptive methods to unaccompanied adolescent girls. Adolescents who have reached the age of majority enjoy, in terms of access to FP services, benefits provided by laws and other policies in force [18] [20] [38]. Until 2018, the Congolese penal code which prohibits FP remained unchanged [39] [40]. Even, two years after its promulgation, the law on public health has not yet been applied, as none of the implementation measures are not yet finalized. Regulatory problems in the DRC also result in the virtual absence of specific policies focused on the use of particular contraceptive methods (i.e. subsidization of FP services for teenagers; prescription of implant, DIU and others), as is the case in some countries [30]. Our results show that the process of formulating policies in the DRC remains long and complex; adolescents and health providers are not sufficiently involved in the establishment of FP policies. The laws give to minors less opportunity to express their opinion; it forces them to submit to parental authority for the satisfaction of their health needs [36]. These facts violate the eighth recommendation of the WHO to ensure respect for human rights in the provision of contraceptive information and services [13].

Of all FP policies, the useful information booklet on health services adapted to the needs of adolescents and young people [41]; and the norms of health interventions adapted to adolescents and young people [42] are more informative on FP for both providers and adolescents. They describe the criteria required for a health facility to be considered as friendly for adolescents and young people. Unfortunately, these documents are also lacking in HFs.

The majority of instructions developed by the $\mathrm{MOH}$ aim to regulate and promote modern contraceptive methods as more effective than traditional me- 
thods [18] [20]. Apart from the strategic plan for the health and well-being of adolescents and young people [22], there is little emphasis on traditional methods and adolescents' education in SRH. Yet, studies indicate that in the DRC, adolescents have unmet needs in both modern and traditional contraceptive methods. The 2018 MICS survey [23] estimated unmet needs in FP among adolescent girls at $33 \%$ and $56 \%$ for those living in couple and those not in a couple respectively. In practice, some adolescents use traditional contraceptive methods; those in school receive sex education often considered as taboo in families [25] [26].

Adolescents make up a significant portion of the world's population. In view of their important role, their better health is currently one of the global priorities of the Global Sustainable Development Goals (SDGs) [43]. Some recent FP policies in the DRC do not rely on any evidence from robust studies. Even, they are poorly evaluated, unlike other countries around the world [44].

In view of the current expansion of contraceptive services, it is important to improve their quality. Recent studies have shown that FP activities are not systematically organized within HFs in the DRC [16] [21]; and that some HFs do not ensure the services meeting the needs of adolescents [31]. This situation could be due to the unavailability of operational instructions and guidelines; the lack of trained FP providers and the poor quality of supervision, well known as a mean to improve the quality of services [45]. It is important to monitor the social needs of adolescents by applying the tool published in 2013 that analyzes the respect of the rights of children and adolescents [46].

According to this study, the weak regulation of FP could largely explain why contraceptive prevalence remains low among adolescent girls and the adolescent fertility rate higher in the DRC [23]; despite the combined efforts in terms of extension of FP services between 2014 [21] and 2018 [47]. Sexuality education and awareness programs for adolescent girls in the prevention of early and unwanted pregnancies are not systematically formalized. Parents, teachers, health care providers and other structures in charge of adolescent sexuality education do not feel an obligation to provide them with the quality information and service's needs. There are no specific laws and policies obliging health care providers to disregard their biases before offering FP services to adolescents. There is also no clear policy defining financial accessibility to contraceptive services for adolescent girls. The rapid expansion of FP services is more palpable in urban areas than in rural areas where the needs are important [21], but there is no clear political orientation in this direction.

Also, the existing laws, regulations and policies are insufficiently enforced; for example, a national study estimated in 2018 at $29 \%$ the proportion of early marriages among adolescent girls [23]; while the law on child protection is supposed to fight against early marriages.

\section{Strengths and Limitations}

This study was the first that combined qualitative and quantitative approaches to 
investigate the FP policy environment at the national, provincial and local levels of the MOH in the DRC. The main limitation could be linked to the document review procedure that may not have been exhaustive; due to the problem of archiving documents. However, in order to minimize this limit, the study results were validated by the $\mathrm{MOH}$ officials.

\section{Conclusion}

It is undeniable that the adolescent is an important and relevant target of FP. The results of this study showed that FP among adolescents in the DRC faces several challenges, in particular the inadequate regulation and standardization. Current policies are unsuitable with international standards in FP. Adolescents do not have a legal basis guaranteeing secure access and the unhindered uptake of contraceptive services. To improve access to and use of contraceptive services and methods by adolescents, it is therefore important that the evidence-based regulations be established; improved; monitored; and evaluated in order to boost access to and uptake of FP services by adolescents. Improving the use of the FP service by adolescents should contribute to the better health status of women, families and the community.

\section{Prospect}

In perspective, there is a need to discuss with adolescents about important aspects of FP that they would like to include in policies.

\section{Ethics Approval and Consent to Participate}

The research protocol was reviewed and approved by the Ethics Committee of the School of Public Health of Kinshasa (ESPK) under approval number ESP/CE/027/2018. Before collecting the data, we obtained authorization from national, provincial, and local health authorities.

\section{Acknowledgements}

The authors are grateful to all those who made this study possible, especially the health officials at the national and provincial level, and managers of the health facilities. We sincerely thank the project "Renforcement Institutionnel pour les Politiques de Santé basées sur l'Evidence en République Démocratique du Congo (RIPSEC)" for supporting the process leading up to the finalization of this manuscript.

\section{Conflicts of Interest}

The authors declare no conflicts of interest regarding the publication of this paper.

\section{References}

[1] Darroch, J.E., Woog, V., Bankole, A. and Ashford, L.S. (2016). Adding It Up: Costs 
and Benefits of Meeting Contraceptive Needs of Adolescents. Guttmacher Institute, New York.

https://www.guttmacher.org/sites/default/files/report_pdf/adding-it-up-adolescents -report.pdf

[2] Chae, S., Kayembe, P.K., Philbin, J., Mabika, C. and Bankole, A. (2016) The Incidence of Induced Abortion in Kinshasa, Democratic Republic of Congo. PLoS ONE, 12, e0184389. https://doi.org/10.1371/journal.pone.0184389

[3] Hoffman, S.D. and Maynard, R.A. (2008) Kids Having Kids: Economic Costs and Social Consequences of Teen Pregnancy. Urban Institute Press, Washington DC.

[4] Collins, T. (2005) Health Policy Analysis: A Simple Tool for Policy Makers. Public Health, 119, 192-196. https://doi.org/10.1016/j.puhe.2004.03.006

[5] Cordova-Pozo, K., Borg, S., Hoopes, A.J., Camacho-Hubner, A.V., Corrales-Ríos, F., Salinas-Bomfim, A. and Chandra-Mouli, V. (2017) How Do National Contraception Laws and Policies Address the Contraceptive Needs of Adolescents in Paraguay? Reproductive Health, 14, 88.

https://doi.org/10.1186/s12978-017-0344-Z

[6] Melgar, J.L.D., Melgar, A.R., Festin, M.P.R., Hoopes, A.J. and Chandra-Mouli, V. (2018) Assessment of Country Policies Affecting Reproductive Health for Adolescents in the Philippines. Reproductive Health, 15, 205.

https://doi.org/10.1186/s12978-018-0638-9

[7] Gilson, L. (2012) Health Policy and Systems Research, a Methodology Reader. Alliance for Health Policy and Systems Research and World Health Organization. https://www.who.int/alliance-hpsr/alliancehpsr_reader.pdf

[8] Parkinson, C. and White, M. (2013) Inequalities, the Arts and Public Health: Towards an International Conversation. Arts Health, 5, 177-189. https://doi.org/10.1080/17533015.2013.826260

[9] Journal officiel de la RDC (2002) Arrêté ministeriel. $\mathrm{N}^{\circ} 1250 / \mathrm{CAB} / \mathrm{MIN} / \mathrm{S} / \mathrm{AJ} / \mathrm{VKIZ} / 009 / 2001$ du 9 décembre 2001 portant création et organisation du programme national de la santé de la reproduction du Ministère de la Santé publique. http://www.leganet.cd

[10] Programme National de la Santé des Adolescents de la République Démocratique du Congo (2016) Plan stratégique national de la santé et du bien-être des adolescents et jeunes 2016-2020.

[11] Clarke, D. (2016) Law, Regulation and Strategizing for Health. In: Schmets, G., Rajan, D. and Kadandale, S., Eds., Strategizing National Health in the 21 st Century: $A$ Handbook, World Health Organization, Geneva, Chapter 10.

[12] Hardee, K. and Jordan, S. (2019) Contributions of FP2020 in Advancing Rights-Based Family Planning. Upholding and Advancing the Promises of Cairo. Family Planning 2020.

http://www.familyplanning2020.org/sites/default/files/Our-Work/RBFP/10.24.19_F P2020_RBFP_Paper.pdf

[13] World Health Organization (2014) Ensuring Human Rights in the Provision of Contraceptive Information and Services: Guidance and Recommendations. http://apps.who.int/iris/bitstream/10665/102539/1/9789241506748_eng.pdf?ua=1

[14] World Health Organization (2011) Guidelines on Preventing Early Pregnancy and Poor Reproductive Health Outcomes among Adolescents in Developing Countries. http://www.who.int/reproductivehealth/publications/adolescence/9789241502214/en

[15] République Démocratique du Congo, Ministère du plan (2011) Document de Stratégie de Croissance et de Réduction de la Pauvreté-DSCRP 2. 
[16] Mukaba, T., Binanga, A., Fohl, S. and Bertrand, J.T. (2015) Family Planning Policy Environment in the Democratic Republic of the Congo: Levers of Positive Change and Prospects for Sustainability. Global Health: Science and Practice, 3, 163-173. https://doi.org/10.9745/GHSP-D-14-00244

[17] Ministère de la santé de la République Démocratique du Congo (2008) Politique nationale de la santé de reproduction. Kinshasa.

http://planificationfamiliale-rdc.net/documentation-sur-la-rdc-documents-officiel.php

[18] République Démocratique du Congo (2018) Loi N¹8/035 du 13 décembre 2018 fixant les principes fondamentaux relatifs à l'organisation de la santé publique. Journal official de la République Démocratique du Congo.

http://www.leganet.cd/Legislation/Droit\%20Public/SANTE/Loi.18.035.13.12.2018.h $\underline{\mathrm{tml}}$

[19] Ministère de la santé de la République Démocratique du Congo. Plan national de développement sanitaire 2019-22: Vers la couverture sanitaire universelle.

[20] République Démocratique du Congo (2014) Planification familiale: Plan stratégique national à vision multisectorielle 2014-2020. Kinshasa.

[21] Mpunga, M.D., Lumbayi, J.-P., Dikamba, M.N., Mwembo, T.A. and Mapatano, M.A. (2017) Availability and Quality of Family Planning Service in DR Congo: High Potential Improvement, Global Health: Science and Practice.

https://doi.org/10.9745/GHSP-D-16-00205

[22] Muanda, F.M., Gahungu, N.P., Wood, F. and Bertrand, J.T. (2018) Attitudes toward Sexual and Reproductive Health among Adolescents and Young People in Urban and Rural DR Congo. Reproductive Health, 15, 74.

https://doi.org/10.1186/s12978-018-0517-4

[23] Institut National de Statistiques (2019) Enquête par grappes à indicateurs multiples, 2017-2018, rapport de résultats de l'enquête. Kinshasa, République Démocratique du Congo.

[24] Shah, C.J., Solanki, V. and Mehta, H.B. (2011) Attitudes of Adolescent Girls towards Contraceptive Methods. AMJ, 4, 43-48.

[25] Capurchande, R., Coene, G., Schockaert, I., Macia, M. and Meulemans, H. (2016) "It Is Challenging... Oh, Nobody Likes It!": A Qualitative Study Exploring Mozambican Adolescents and Young Adults' Experiences with Contraception. BMC Women's Health, 16, 48. https://doi.org/10.1186/s12905-016-0326-2

[26] Tshitenge, S.T., Nlisi, K., Setlhare, V. and Ogundipe, R. (2018) Knowledge, Attitudes and Practice of Healthcare Providers Regarding Contraceptive Use in Adolescence in Mahalapye, Botswana. South African Family Practice, 60, 181-186. https://doi.org/10.1080/20786190.2018.1501239

[27] Tilahun, M., Mengistie, B., Egata, G. and Reda, A.A. (2012) Health Workers' Attitudes toward Sexual and Reproductive Health Services for Unmarried Adolescents in Ethiopia. Reproductive Health, 9, Article No. 19.

http://www.reproductive-health-journal.com/content/9/1/19 https://doi.org/10.1186/1742-4755-9-19

[28] Muanda, M., Gahungu Ndongo, P., Taub, L.D. and Bertrand, J.T. (2016) Barriers to Modern Contraceptive Use in Kinshasa, DRC. PLoS ONE, 11, e0167560. https://doi.org/10.1371/journal.pone.0167560

[29] Mpunga, D.M., Chenge, F.M., Mapatano, M.A. and Wembodinga, G.U. (2018) Exploring the Adequacy of Family Planning Services to Adolescents Needs: Results of a Cross-Sectional Study from Two Settings in the Democratic Republic of the Congo. Health Education and Public Health, 2, 131-141. 
https://doi.org/10.31488/heph.111

[30] Pr Florence Taboulet (2018) La contraception d'urgence chez les mineures. Une offre illimitée en manque d'évaluation. Médecine \& Droit, 2018, 31-38. https://doi.org/10.1016/j.meddro.2018.02.002

[31] Sivagurunathan, C., Umadevi, R., Rama, R. and Gopalakrishnan, S. (2015) Adolescent Health: Present Status and Its Related Programmes in India. Are We in the Right Direction? Journal of Clinical and Diagnostic Research, 9, LE01-LE06.

http://www.jcdr.net https://doi.org/10.7860/JCDR/2015/11199.5649

[32] WHO, UNAIDS (2015) Global Standards for Quality Health-Care Services for Adolescents. A Guide to Implement a Standards-Driven Approach to Improve the Quality of Health-Care Services for Adolescents. Volume 1.

https://apps.who.int/iris/bitstream/handle/10665/183935/9789241549332_vol1_eng. pdf;jsessionid=0D0D425BBEFE88F11EE173653F5B767F?sequence $=1$

[33] Walt, G. and Gilson, L. (1994) Reforming the Health Sector in Developing Countries: The Central Role of Policy Analysis. Health Policy and Planning, 9, 353-370. https://doi.org/10.1093/heapol/9.4.353

[34] Ministère de la santé (2017) Cadre et structures organiques du Secrétariat Général à la santé publique. République Démocratique du Congo.

[35] République Démocratique du Congo, Comité Technique Multisectoriel Permanent (CTMP/PF) (2015) Loi sur la santé de reproduction en République Démocratique du Congo. Recueil d'arguments. Consulté le 28 mai 2019.

http://planificationfamiliale-rdc.net/media/Recueil\%20darguments\%20Loi\%20SR.pdf

[36] Journal officiel de la République Démocratique du Congo (2009) Loi N09/001 du 10 janvier 2009 portant protection de l'enfant. Consulté le 30 juin 2019. http://www.leganet.cd/Legislation/JO/2009/L.09.001.10.01.09.htm

[37] Journal officiel de la République Démocratique du Congo (2016) Code de la famille de la République Démocratique du Congo. Consulté le 25 septembre 2019. https://www.leganet.cd/Legislation/Code\%20de\%20la\%20famille/CDF.2017.pdf

[38] Journal officiel de la République Démocratique du Congo (2015) Loi n 15/013 du $1^{\mathrm{er}}$ août 2015 portant modalités d'application des droits de la femme et de la parité. Consulté le 15 juillet 2019.

https://leganet.cd/Legislation/Droit\%20Public/DH/Loi.15.013.01.08.html

[39] Journal officiel de la République Démocratique du Congo (2006) Loi n 06/018 du 20 juillet 2006 modifiant et complétant le Décret du 30 janvier 1940 portant Code pénal congolais. Consulté le 20 septembre 2019.

http://leganet.cd/Legislation/DroitPenal/Loi.06.018.20.07.3006.htm

[40] Journal officiel de la République Démocratique du Congo (2015) Loi no 15/022 du 31 décembre 2015 modifiant et complétant le Décret du 30 janvier 1940 portant Code penal. Consulté le 22 septembre 2019. https://leganet.cd/Legislation/DroitPenal/Loi.15.022.31.12.2015.html

[41] République Démocratique du Congo, Programme National de la santé des adolescents (2017) Livret sur la santé sexuelle et reproductive des adolescents et jeunes pour les prestataires des services de santé communautaires: pairs éducateurs et mentors.

[42] République Démocratique du Congo, Programme National de la santé des adolescents (2014) Standards des services de sante adaptes aux adolescents et jeunes.

[43] Organisation Mondiale de la Santé (2015) 2015-2030: Les 17 objectifs de développement durable. https://www.who.int/topics/sustainable-development-goals/fr/

[44] Vialla, F., Faure, M., Martinez, É., Bourret, R. and Vauthier, J.-P. (2015) Mineur et 
secret médical-Le secret sur son état de santé demandé par le mineur à l'égard de ses parents: De la reconnaissance d'un droit à sa mise en œuvre concrète. Médecine \& Droit, 2015, 79-89. https://doi.org/10.1016/j.meddro.2015.04.001

[45] Bosch-Capblanch, X., Liaqat, S. and Garner, P. (2011) Managerial Supervision to Improve Primary Health Care in Low- and Middle-Income Countries. Cochrane Database of Systematic Reviews, No. 9, CD006413.

https://doi.org/10.1002/14651858.CD006413.pub2

[46] Taghizadeh, M.H., Bahreini, A., Ajilian, A.M., Fazli, F. and Saeidi, M. (2016) Adolescence Health: The Needs, Problems and Attention. International Journal of Pediatrics, 4, 1423-1438.

[47] Kwete, D., Binanga, A., Mukaba, T., Nemuandjare, T., Mbadu, M.F., Kyungu, M.-T., Sutton, P. and Bertrand, J.T. (2018) Family Planning in the Democratic Republic of the Congo: Encouraging Momentum, Formidable Challenges. Global Health: Science and Practice, 6, 40-54. https://doi.org/10.9745/GHSP-D-17-00346

\section{Abbreviations}

FP: Family Planning

DRC: Democratic Republic of the Congo

HF: Health Facility

SRH: Sexual and Reproductive Health

MOH: Ministry of Health

DFSGH: Department of Family and Special Groups' Health

NRHP: National Reproductive Health Program

NAHP: National Adolescent Health Program

NSHP: National School Health Program

PDH: Provincial Division of Health

CTMP/PF: Permanent Multi-sectoral Technical Committee for Family Planning CCT-SS: Health Sector Technical Coordination Committee

GTT: Technical Working Group

CPP-SS: Provincial Health Sector Steering Committee

DSCRP2: Second Generation Growth and Poverty Reduction Strategy Document ASRH: Adolescent Sexual and Reproductive Health

MNCH: Maternal, Newborn, and Child Health

HD: Health District 